University of Wollongong

Research Online

Faculty of Social Sciences - Papers (Archive) Faculty of Arts, Social Sciences \& Humanities

2014

Diversion of prescribed opioids by people living with chronic pain: Results from an Australian community sample

Jessica Belcher

University of New South Wales

Suzanne Nielsen

University of New South Wales

Gabrielle Campbell

University of New South Wales

Raimondo Bruno

University of Tasmania

Bianca Hoban

University of New South Wales

See next page for additional authors

Follow this and additional works at: https://ro.uow.edu.au/sspapers

Part of the Education Commons, and the Social and Behavioral Sciences Commons

Research Online is the open access institutional repository for the University of Wollongong. For further information contact the UOW Library: research-pubs@uow.edu.au 


\title{
Diversion of prescribed opioids by people living with chronic pain: Results from an Australian community sample
}

\begin{abstract}
Introduction and Aims There has been an increase in prescription of opioids for chronic non-cancer pain, and concern exists over possible diversion of prescription opioids to the illicit marketplace. Recent media coverage suggests that elderly patients sell their prescribed opioids for additional income. This study investigated the extent to which an Australian community sample of chronic pain patients prescribed opioids reported supplying their prescribed opioids to others. Design and Methods Participants living with chronic non-cancer pain and prescribed opioids for their pain $(n=952)$ were recruited across Australia via advertisements at pharmacies. A telephone interview included questions about their pain condition and opioid medication. Results Participants had been living with pain for a mean of 14.2 years; most common conditions included chronic back/neck problems and arthritis/rheumatism. Around half (43\%) were currently prescribed one opioid, and $55 \%$ had been prescribed $2-5$ opioids; the most common was oxycodone. Forty-two participants (4\%) reported ever supplying prescribed opioids to another person; one participant reported receiving payment. Participants who supplied opioids to others were younger (odds ratio $0.97,95 \%$ confidence interval $0.95-0.99$ ) and engaged in a greater number of aberrant behaviours relating to their opioid medication (odds ratio $1.77,95 \%$ confidence interval 1.45-2.17), including tampering with doses, taking opioids by alternative routes, seeing doctors to obtain extra opioids and refilling prescriptions early. Discussion and Conclusion Few people with chronic non-cancer pain divert their opioids to others. Media reports of elderly patients selling their opioids to supplement their income may be reflective of exceptional cases. Future studies may investigate the extent to which other patient groups divert prescription opioids to the illicit marketplace.
\end{abstract}

\section{Keywords}

prescribed, opioids, people, living, diversion, chronic, sample, pain:, results, australian, community

\section{Disciplines}

Education | Social and Behavioral Sciences

\section{Publication Details}

Belcher, J., Nielsen, S., Campbell, G., Bruno, R., Hoban, B., Larance, B., Lintzeris, N. \& Degenhardt, L. (2014). Diversion of prescribed opioids by people living with chronic pain: Results from an Australian community sample. Drug and Alcohol Review, 33 (1), 27-32.

\section{Authors}

Jessica Belcher, Suzanne Nielsen, Gabrielle Campbell, Raimondo Bruno, Bianca Hoban, Briony K. Larance, Nicholas Lintzeris, and Louisa Degenhardt 


\section{Diversion of prescribed opioids by people living with chronic pain: Results from an Australian community sample}

Jessica Belcher, $\mathrm{PhD}^{1}$ Suzanne Nielsen, $\mathrm{PhD}^{2}$ Gabrielle Campbell ${ }^{1}$, Raimondo Bruno, $\mathrm{PhD}^{3}$,

Bianca Hoban ${ }^{1}$, Briony Larance, PhD $^{1}$ Associate Professor Nicholas Lintzeris, PhD $^{2,4}$

Professor Louisa Degenhardt, $\mathrm{PhD}^{1,5}$

\footnotetext{
${ }^{1}$ National Drug and Alcohol Research Centre, University of New South Wales, Australia

${ }^{2}$ Sydney University, Australia

${ }^{3}$ University of Tasmania, Australia

${ }^{4}$ The Langton Centre, South East Sydney Local Health District (SESLHD) Drug and Alcohol Services, Australia

${ }^{5}$ School of Population and Global Health, University of Melbourne, Australia
}

Corresponding author: Louisa Degenhardt

Email: I.degenhardt@unsw.edu.au

Word count: 2274 


\begin{abstract}
Introduction and aims: There has been an increase in prescription of opioids for chronic non-cancer pain, and concern exists over possible diversion of prescription opioids to the illicit market place. Recent media coverage suggests that elderly patients sell their prescribed opioids for additional income. This study investigated the extent to which an Australian community sample of chronic pain patients prescribed opioids reported supplying their prescribed opioids to others.

Design and methods: Participants living with chronic non-cancer pain and prescribed opioids for their pain ( $n=952)$ were recruited across Australia via advertisements at pharmacies. A telephone interview included questions about their pain condition and opioid medication.
\end{abstract}

Results: Participants had been living with pain for a mean of 14.2 years; most common conditions included chronic back/neck problems and arthritis/rheumatism. Around half (43\%) were currently prescribed one opioid; $55 \%$ had been prescribed 2-5 opioids; the most common was oxycodone. Forty-two participants (4\%) reported ever supplying prescribed opioids to another person; one participant reported receiving payment. Participants who supplied opioids to others were younger (OR 0.97, 95\% Cl 095-0.99) and engaged in a greater number of aberrant behaviours relating to their opioid medication (OR 1.77, $95 \% \mathrm{Cl}$ 1.45-2.17) including tampering with doses, taking opioids by alternative routes, seeing doctors to obtain extra opioids and refilling prescriptions early.

Discussion and conclusion: Few people with chronic non-cancer pain divert their opioids to others. Media reports of elderly patients selling their opioids to supplement their income may be reflective of exceptional cases. Future studies may investigate the extent to which other patient groups divert prescription opioids to the illicit market place. 


\section{Introduction}

In the past decade there has been an increase in prescribed opioids for chronic non-cancer pain, ${ }^{1-4}$ with concern over concomitant increases in dependent use and overdose. ${ }^{125}$ This concern has arisen in parallel with concerns about the appropriateness of opioids in the longer term for the management of chronic non-cancer pain, ${ }^{6}$ in contrast to acceptance of opioids as 'essential medicines' for the management of cancer pain. ${ }^{7}$

Opioids are one of the most frequently borrowed and shared prescription medications ${ }^{8-10}$. Research suggests that the majority of people within the general population who borrow prescription opioids obtain them from a family member or friend. ${ }^{11}{ }^{14}$ In an Australian survey of drug treatment clients that reported regular non-medical pharmaceutical use ${ }^{12}$ over a third of the sample gave away opioids prescribed for them. Further, among this sample most pharmaceutical opioids used over the four weeks prior to entry into treatment were not sourced directly from a prescriber, but were bought from a friend, from the illicit market, or were a gift from a friend or partner. There has therefore been concern over the possibility that there is diversion of prescribed opioids from patients to the illicit market, which may be partially driving extra-medical use and dependence. ${ }^{13} 14$

Media coverage suggests elderly patients prescribed opioids for chronic pain sell them to supplement their income, referred to as "fossil pharming". ${ }^{15} 16$ There is limited data on this issue, and existing data on the extent to which elderly chronic pain patients provide opioids to others has been mainly qualitative. ${ }^{17}$ However the possibility that older people are diverting their opioids to the illicit market is of concern given that, for example, Australian people aged 60 years and older receive around two thirds of morphine prescriptions, and three quarters of oxycodone prescriptions. ${ }^{1}$ To further address this possibility, we investigated the extent to which people living with chronic pain supplied their prescribed opioids to others, using data from an Australian community sample. 


\section{Methods}

The data reported here are from the first 952 participants recruited into the Pain and Opioids IN Treatment (POINT) cohort (http://ndarc.med.unsw.edu.au/project/point-studypain-and-opioids-treatment). This study is intended to follow participants at multiple points over a two year period. The major aims of the study are to examine the natural history of prescribed opioid use; examine the predictors of adverse events; and identify factors that predict poor self-reported pain relief and other outcomes. This study received ethical approval from the University of New South Wales.

With National Pharmacy Guild approval, we contacted 2,915 pharmacies from a national database of Australian pharmacies. All Tasmanian pharmacies were sampled first, followed by a random sample of pharmacies from NSW and then across Australia. Research staff contacted each selected pharmacy via phone to a) briefly explain the study and b) ask whether they would help with study recruitment.

Of the pharmacies selected, 1,121 (38\%) agreed to help with recruitment. The spread of pharmacies mirrored the geographic distribution of the Australian population. Pharmacists that assisted with recruitment asked customers that had been prescribed a schedule 8 opioid (i.e., drugs of dependence that are subject to additional regulatory controls regarding their manufacture, supply, distribution, possession and $u \mathrm{e}^{18}$ ) if they would be interested in taking part in a study on pain and opioids. Pharmacists were reimbursed $\$ 20$ for each eligible customer that was referred to the study. Interested people were invited to contact, or send in their contact details to the study team. The research team assessed each interested person's eligibility and explained the study in full before gaining voluntary informed consent to participate. As the current study was part of a large survey (encompassing the aims outlined in the previous paragraph) participants were not specifically told that the interview would include questions regarding diversion of their medication, nor was this the focus of the questions that were asked. It was explained to participants that their data would be kept confidential and would not be shared with anyone outside of the research team unless they threatened harm to themselves or others (as required by university ethics). Participants were given the option to decline to answer any of the questions throughout the interview. 
Eligible participants were those who met the following criteria: a) English speaking, b) prescribed opioids (e.g., oxycodone) for 6 weeks or more, c) living with chronic pain (defined as pain for three months or longer), d) no current cancer, and e) not currently undergoing opioid substitution treatment for the management of opioid dependence developed through illicit opioid use. Telephone interviews with participants were conducted by trained interviewers with a minimum of four years undergraduate training in psychology. Participants were reimbursed for their time $(\$ 40)$.

Questions used in this analysis included demographics such as age, gender and weekly income, current pain medication, number of opioid medications currently prescribed and the duration of current opioid treatment episode. Participants were also asked whether they had ever supplied or offered prescribed opioids to others (yes/no), if so, how frequently, how long ago, whether they received payment, and to whom they supplied/offered prescribed opioids.

All participants were asked questions regarding aberrant opioid-related behaviours over the past three months, using the Opioid Related Behaviours in Treatment scale (ORBIT) ${ }^{19}$. The scale comprises 10 items (e.g., 'Over the past 3 months, I have asked my doctor for an increase in my prescribed dose') and each item was scored dichotomously (yes/no) in the current study. The ORBIT scale was developed for use among Australian patients receiving opioid therapy for pain or opioid dependence in both clinical and research settings. The scale has demonstrated strong internal consistency (Cronbach's alpha $=0.85) .{ }^{19}$ 


\section{Results}

Of the 1778 individuals referred to the study by pharmacists, $472(27 \%)$ were ineligible. Of the remainder, 952 participated (53\%, 73\% of eligible participants), 228 declined to take part in the study $(13 \%, 17 \%$ of eligible participants), and 106 felt they were too unwell to take part in the study $(6 \%, 8 \%$ of eligible participants). Fifty-one participants were eligible but had not completed their baseline interview at the time of this study.

The sample was approximately half male (44.5\%) with a mean age of 58 years (range 19-89). Participants had been living with chronic pain for a mean of 14.2 years (SD $=12.4$ ); just under three quarters $(70.7 \%, n=296)$ had two or more current pain conditions. The most common pain conditions included chronic back or neck problems and arthritis/rheumatism.

Around half the sample were currently prescribed one opioid $(n=403)$, the other half were prescribed two to five opioids $(n=528)$. The most commonly prescribed opioid was oxycodone (see Table 1).

\section{Table 1 about here}

As observed in Table 2, 42 participants (4\%) reported ever supplying/offering prescribed opioids to another person. Most participants reported doing so on one to 12 occasions, with median of 2 times, and a median of 6 months ago (range 1-276 months). One participant supplied prescribed opioids to their partner more than 100 times (no payment). Participants reported offering prescribed opioids to a partner $(n=7)$, relative or friend $(n=21)$ and three participants refused to specify. One participant reported receiving payment for supplying their friend prescribed opioids on four occasions. More than half of the participants who supplied/offered prescribed opioids (26 of 42 participants) were prescribed oxycodone; those who supplied/offered others their prescribed opioids were more likely to be currently prescribed hydromorphone $(n=5,11.9 \%)$ than participants who did not report such behaviour ( $n=37,4.1 \%)$.

As seen in Table 1, participants who reported supplying/offering prescribed opioids were significantly younger; only 11 participants over 65 years reported supplying/offering prescribed opioids to others. Participants who supplied/offered prescribed opioids were no more likely to be male or female. Further, participants on a lower income (i.e., \$0-399) were 
no more likely to have supplied/offered prescribed opioids compared to participants on higher incomes.

\section{Table 2 about here}

As observed in Table 1, the two groups did not differ with regard to the length of time they had been prescribed opioids. However, participants who reported supplying/offering their prescribed opioids to others were currently prescribed a significantly greater number of opioids $(M=2.05, S D=0.85)$ than those who did not $(M=1.67, S D=0.79, O R 1.70,95 \% \mathrm{Cl}$ 1.20-2.40).

Participants who supplied/offered opioids also endorsed more aberrant opioid medication behaviours on the ORBIT scale $(M=1.61, S D=1.97)$ compared to participants who did not $(\mathrm{M}=0.53, \mathrm{SD}=0.90 ; \mathrm{OR} 1.77,95 \% \mathrm{Cl}$ 1.45-2.17; Table 1). Considering the individual ORBIT items (Table 3), in comparison with participants who did not report supplying/offering their prescribed opioids to others, participants who did were significantly more likely to: a) ask their doctor for an early renewal of their prescription because they had run out early (26\% vs. $10.1 \%$; OR $3.17,95 \% \mathrm{Cl} 1.54-6.51)$, b) go to a different doctor to get their opioid medication without telling their normal doctor (4.8\% vs. 0.9\%; OR 5.59, 95\% $\mathrm{Cl} 1.15-27.20)$, c) alter their dose, e.g. cutting patches or pills in half when not advised to do so ( $21 \%$ vs.4\%; OR $6.21,95 \% \mathrm{Cl} 2.77-13.89)$, and d) take their opioids by a different route than prescribed (e.g. injecting) (9.5\% vs. 0.3\%; OR 31.58, 95\% Cl 6.83-146.09).

Table 3 about here 


\section{Discussion}

Our study suggests that it is uncommon for people living with chronic pain to sell prescribed opioids to supplement income, or to offer it to others, and those who do supply/offer opioid medications to others, do so infrequently. Four percent of participants (42 out of the sample of 952) had ever engaged in medication sharing, and those that had supplied/offered their medication reported doing this a median of 2 times in their lifetime. A review of opioid related diversion suggests that several pathways of prescription opioid diversion exist including theft, doctor shopping and fraud ${ }^{20}$. Further, rates of diversion from other sources, for example college students prescribed opioids for acute pain conditions, have been found to be as high as 29 percent (50 of 171 participants) ${ }^{21}$. The smaller number of participants who diverted within the current study may indicate that other populations could be providing a larger amount of opioids to the illicit market place and future studies could aim to further investigate diversion within these groups.

With respect to the suggestion that elderly people may be likely to supply/offer their prescribed opioids to others, participants who did report such behaviour were significantly younger compared to those who did not, and only 11 were aged over 65 years. Over half the participants who reported supplying/offering prescribed opioids were on a lower income, however this was reflective of the sample as a whole. Only one participant reported receiving payment for their prescribed opioids. Rather, participants in the current study typically offered prescribed opioids to a family member or friend. Such findings are consistent with previous research that suggests the majority of people who borrow prescription opioids obtain them informally ${ }^{111222}$.

Participants who reported supplying/offering their prescribed opioids to others endorsed a significantly greater number of aberrant behaviours, which included early renewal of their opioid prescriptions, seeking opioids from more than one doctor, tampering with their dose and taking opioids by a different route than prescribed. It seems that those who are willing to supply/offer their prescription opioids to others are less likely to follow doctors' recommendations in general with regards to their medication.

Our study provides a preliminary indication of the characteristics of chronic pain patients who divert their prescribed opioids. There was a small proportion of participants who 
diverted their medication (4\%). Although there was no corroborative evidence to indicate that participants were reporting truthfully about their sharing of prescription opioids, they were informed that their responses would be de-identified and confidential; this has traditionally resulted in valid reports around illicit drug use. ${ }^{23}$ Further, participants had nothing to gain from misrepresenting their behaviours, increasing the reliability of selfreport in this context. ${ }^{24}$ While, there were no consequences to participants for disclosing diversion activities, it may be that people who engaged in such activities declined to take part in the study altogether due to fear that their responses may filter back to their pharmacy or legal authority. The chronic pain population within the current study is similar in terms of characteristics (i.e., age, gender distribution, length of time prescribed opioids, number of opioids prescribed) to other studies of chronic non-cancer pain patients, suggesting that our sample may not be overly biased in this regard. ${ }^{25} 26$

It is possible that the results may have been affected by social desirability bias, whereby some chronic pain patients were reluctant to report supplying or offering their prescribed opioid. However, rather than diverting medications for financial gain, it appears most instances of medication sharing were giving their medication to family members or friends in an attempt to be helpful, which may not necessarily be perceived as socially undesirable.

Media reports ${ }^{1516}$ and previous research ${ }^{4}$ indicating that elderly people are an important source of prescription opioids for the illicit market is not consistent with our findings. Our sample of people who were living with chronic pain did not appear to be engaging in considerable diversion. This may not be surprising given that they have current pain, and might be expected to prefer to use opioids to assist with management of this pain. This does suggest that a more important source of illicit opioids may be from patients who do not regularly need opioids for pain, or other sources. It seems clear that given the apparent scale of prescription opioid misuse among illicit drug users in Australia (e.g., ${ }^{27}$ ), that there must be considerable diversion occurring from other channels. Further research is needed to understand how prescribed opioids are diverted to the illicit marketplace. 


\section{Acknowledgements}

The authors had full access to all of the data in the study. Funding for the work undertaken for this manuscript was provided by the National Health and Medical Research Council (NHMRC). LD and SN are supported by NHMRC Research Fellowships. The National Drug and Alcohol Research Centre at the University of NSW is supported by funding from the Australian Government under the Substance Misuse Prevention and Service Improvements Grants Fund.

\section{Conflicts of interest}

LD, SN, NL and BL have received untied educational grants from Reckitt Benckiser. Reckitt Benckiser had no knowledge of this study. 


\section{References}

1. Roxburgh A, Bruno R, Larance B, Burns L. Prescription of opioid analgesics and related harms in Australia. Med J Aust 2011;195(5):280-84.

2. Roxburgh A, Burns L, Drummer OH, Pilgrim J, Farrell M, Degenhardt L. Trends in fentanyl prescriptions and fentanyl-related mortality in Australia. Drug and Alcohol Review 2013:n/a-n/a.

3. Leong M, Murnion B, Haber P. Examination of opioid prescribing in Australia from 1992 to 2007. Internal medicine journal 2009;39(10):676-81.

4. Cicero TJ, Inciardi JA, Surratt H. Trends in the use and abuse of branded and generic extended release oxycodone and fentanyl products in the United States. Drug and Alcohol Dependence 2007;91:115-20.

5. Kuehn BM. Methadone Overdose Deaths Rise With Increased Prescribing for Pain. JAMA: the journal of the American Medical Association 2012;308(8):749-50.

6. Kissin I. Long-term opioid treatment of chronic nonmalignant pain: unproven efficacy and neglected safety? Journal of Pain Research 2013;6:513-29.

7. World Health Organization. WHO Essential medicines library: World Health Organization.

8. Ward L, Patel NM, Hanlon A, Eldakar-Hein S, Sherlinski K, Ward SH. Prescription medication borrowing among adult patients at an urban medical center. Journal of Urban Health 2011;88(6):997-1014.

9. Goldsworthy RC, Schwartz NC, Mayhorn CB. Beyond abuse and exposure: framing the impact of prescription-medication sharing. American Journal of Public Health 2008;98(6):1115-21.

10. Ellis J, Mullan J. Prescription medication borrowing and sharing: risk factors and management. Australian family physician 2009;38(10):816.

11. Manchikanti $L$, Singh A. Therapeutic opioids: a ten-year perspective on the complexities and complications of the escalating use, abuse, and nonmedical use of opioids. Pain Physician 2008;11(2 Suppl):S63-88.

12. Nielsen S, Bruno R, Degenhardt L, Carruthers S, Stoove M, Fischer J, et al. The source of pharmaceuticals for problematic users of prescription opioids and benzodiazepines. Med J Aust in press.

13. Inciardi JA, Surratt HL, Cicero TJ, Kurtz SP, Martin SS, Parrino MW. The "black box" of prescription drug diversion. J Addict Dis 2009;28(4):332-47.

14. Inciardi JA, Surratt HL, Kurtz SP, Cicero TJ. Mechanisms of Prescription Drug Diversion Among Drug-Involved Club- and Street-Based Populations. Pain Medicine 2007;8(2):171-83.

15. Medew J. Seniors selling off their drugs. The Sydney Morning Herald. http://www.smh.com.au. Accessed December 10, 2012., November 18, 2012. .

16. Walter S. Officers see more sick and elderly selling prescription drugs. The New York Times: http://www.nytimes.com. Accessed March 13, 2013, September 18, 2010.

17. Inciardi JA, Surratt HL, Cicero TJ, Beard RA. Prescription opioid abuse and diversion in an urban community: the results of an ultrarapid assessment. Pain Medicine 2009;10(3):537-48.

18. Therapeutic Goods Administration. Standard for the Uniform Scheduling of Medicines and Poisons (SUSMP). In: Australian Government Department of Health and Ageing, 
editor. http://www.tga.gov.au/industry/scheduling-poisons-standard.htm. Accessed on 05/09/2013, 2013.

19. Minimising the unintended consequences of opioid treatment: development of a drug behaviour scale for use in Australia. College on Problems of Drug Dependence 74th Annual Meeting; 2012; Palm Springs, CA.

20. Fischer B, Argento E. Prescription opioid related misuse, harms, diversion and interventions in Canada: a review. Pain Physician 2012;15(3):ES191-ES203.

21. Arria AM, Garnier-Dykstra LM, Caldeira KM, Vincent KB, O'Grady KE. Prescription analgesic use among young adults: adherence to physician instructions and diversion. Pain Medicine 2011;12(6):898-903.

22. Fischer B, Bibby M, Bouchard M. The Global Diversion of Pharmaceutical Drugs Nonmedical use and diversion of psychotropic prescription drugs in North America: a review of sourcing routes and control measures. Addiction 2010;105(12):2062-70.

23. Darke S. Self-report among injecting drug users: a review. Drug and Alcohol Dependence 1998;51(3):253-63.

24. Chan D. So why ask me? Are self-report data really that bad? In: Lance CE, Vandenberg RJ, editors. Statistical and Methodological Myths and Urban Legends: Doctrine, verity and Fable in the Organizational and Social Sciences. New York: Taylor \& Francis, 2009:309-36.

25. AlMakadma YS, Simpson K. Opioid therapy in non-cancer chronic pain patients: Trends and efficacy in different types of pain, patients age and gender. Saudi journal of anaesthesia 2013;7(3):291.

26. Blyth FM, March LM, Brnabic AJM, Jorm LR, Williamson M, Cousins MJ. Chronic pain in Australia: a prevalence study. Pain 2001;89(2-3):127-34.

27. Stafford J, Burns L. Australia Drug Trends 2011: Findings from the Illicit Drug Reporting System (IDRS). Australian Drug Trends Series No. 73. Sydney: National Drug and Alcohol Research Centre, University of New South Wales 2012. 
Table 1: Characteristics of chronic pain participants according to whether they reported supplying or offering opioids to others

\begin{tabular}{|c|c|c|c|c|}
\hline & \multicolumn{2}{|c|}{$\begin{array}{c}\text { Supplied or offered opioids to } \\
\text { others }\end{array}$} & \multirow[b]{2}{*}{ OR $(95 \% \mathrm{Cl})$} & \multirow[b]{2}{*}{$\begin{array}{c}\text { Total } \\
\mathrm{N}=952\end{array}$} \\
\hline & $\begin{array}{c}\text { No } \\
n=910\end{array}$ & $\begin{array}{c}\text { Yes } \\
n=42\end{array}$ & & \\
\hline Age in years, mean (SD) & $58.05(13.3)$ & $52.48(14.0)$ & $0.97(0.95-0.99)$ & $57.81(13.4)$ \\
\hline \multicolumn{5}{|l|}{ Gender, n (\%) } \\
\hline Male & $400(44.0)$ & $23(54.8)$ & $1.54(0.83-2.87)$ & $423(44.5)$ \\
\hline Female & $510(55.9)$ & $19(45.2)$ & Ref. & $529(55.4)$ \\
\hline \multicolumn{5}{|l|}{ Weekly income, $n(\%)$} \\
\hline$\$ 800$ or more & $96(10.5)$ & $6(14.3)$ & \multirow{2}{*}{$0.97(.51-1.86)$} & $102(10.7)$ \\
\hline$\$ 400-799$ & $221(24.3)$ & $9(21.4)$ & & $230(24.2)$ \\
\hline$\$ 399$ or less & $590(64.8)$ & $27(64.3)$ & Ref. & $568(59.9)$ \\
\hline \multicolumn{5}{|l|}{ Current prescribed opioids, $\mathbf{n}(\%)$} \\
\hline Morphine & $131(14.4)$ & $7(16.7)$ & $1.19(0.52-2.73)$ & $138(14.5)$ \\
\hline Oxycodone & $472(51.9)$ & $26(61.9)$ & $1.51(0.80-2.85)$ & $498(52.3)$ \\
\hline Codeine & $84(21.7)$ & $7(43.8)$ & $1.64(0.87-3.01)$ & 304 (31.9) \\
\hline Methadone & $35(3.8)$ & $4(9.5)$ & $2.63(0.89-7.78)$ & $39(4.1)$ \\
\hline Buprenorphine & $211(23.2)$ & $11(26.2)$ & $1.18(0.58-2.38)$ & $222(23.3)$ \\
\hline Fentanyl & $132(14.5)$ & $5(11.9)$ & $0.80(0.31-2.06)$ & $137(14.4)$ \\
\hline Tramadol & $132(14.5)$ & $7(16.7)$ & $1.18(0.51-2.71)$ & $139(14.6)$ \\
\hline Hydromorphone & $37(4.1)$ & $5(11.9)$ & $3.12(1.19-8.58)^{*}$ & $42(4.4)$ \\
\hline Dextropropoxyphene & $14(1.5)$ & $1(2.4)$ & $1.56(0.20-12.16)$ & $15(1.6)$ \\
\hline $\begin{array}{l}\text { Length of time prescribed opioids, } \\
\text { months mean (SD) }\end{array}$ & $91.78(99.70)$ & $\begin{array}{c}112.99 \\
(110.18)\end{array}$ & $1.00(0.99-1.00)$ & $92.7(100.2)$ \\
\hline $\begin{array}{l}\text { Number of current prescribed opioids, } \\
\text { mean (SD) }\end{array}$ & $1.67(0.79)$ & $2.05(0.85)$ & $1.70(1.20-2.40)$ & $1.7(0.8)$ \\
\hline ORBIT items rated 'yes', mean (SD) & $0.53(0.90)$ & $1.61(1.97)$ & $1.77(1.45-2.17)$ & $0.58(1.0)$ \\
\hline
\end{tabular}

Note. $\$$ = AUD; ORBIT = Opioid Related Behaviours in Treatment scale ${ }^{*} p<0.05$ 
Table 2: Characteristics of participants who reported supplying/offering their prescription opioids

\begin{tabular}{ll}
\hline Supplied or offered & \\
\hline Number of participants (\% of sample) & $42(4.4)$ \\
Median number of occasions (Range) & $2(1->100)$ \\
Median no, months since last supplied/offered (Range) & $6(1-276)$ \\
Number who received money for prescribed opioids (\% of total sample) & $1(0.1)$ \\
\hline Relationship, $\mathbf{n}$ (\% of those who supplied/offered)* & \\
Partner & $7(21.9)$ \\
Family member & $9(28.2)$ \\
Friend or acquaintance & $12(37.5)$ \\
Dealer & $0(0)$ \\
Refused & $3(6.5)$ \\
\hline${ }_{n}=7$ missing &
\end{tabular}


Table 3: Differences in non-adherent behaviours according to whether participants had supplied their opioids to others

\begin{tabular}{|c|c|c|c|c|}
\hline \multirow[b]{2}{*}{ In the past three months... } & \multicolumn{2}{|c|}{$\begin{array}{l}\text { Supplied or offered } \\
\text { opioids to others }\end{array}$} & \multirow[b]{2}{*}{ OR $(95 \% \mathrm{Cl})$} & \multirow[b]{2}{*}{$\begin{array}{c}\text { Total } \\
\mathbf{N}=952\end{array}$} \\
\hline & $\begin{array}{c}\text { No } \\
\mathrm{n}=910\end{array}$ & $\begin{array}{c}\text { Yes } \\
\mathrm{n}=\mathbf{4 2}\end{array}$ & & \\
\hline & n(yes) (\%) & $\mathrm{n}($ yes) $(\%)$ & & \\
\hline 1. I have asked my doctor for an increase in my prescribed dose & $188(20.8)$ & $14(33.3)$ & $1.90(0.98-3.68)$ & $202(21.2)$ \\
\hline 2. I have asked my doctor for an early renewal of my prescription because I had run out early & $91(10.1)$ & $11(26.2)$ & $3.17(1.54-6.51)^{*}$ & $102(10.7)$ \\
\hline $\begin{array}{l}\text { 3. I have used another person's opioid medication, for example a friend, partner or family } \\
\text { member's medication, or bought it from the street }\end{array}$ & $18(2.0)$ & $4(9.5)$ & $5.18(1.67-16.04)$ & $22(2.3)$ \\
\hline 4. I have saved up my opioid medication, just in case I needed it later & $64(7.1)$ & $6(14.3)$ & $2.19(0.89,5.38)$ & $70(7.4)$ \\
\hline $\begin{array}{l}\text { 5. I have gone to a different doctor to get more opioid medication and didn't tell my normal } \\
\text { doctor about it }\end{array}$ & $8(0.9)$ & $2(4.8)$ & $5.59(1.15-27.20)^{*}$ & $10(1.1)$ \\
\hline $\begin{array}{l}\text { 6. I have asked my doctor for another opioid prescription because either I had lost my } \\
\text { prescription or medication, had had it stolen or someone else had used it }\end{array}$ & $38(4.2)$ & $4(9.5)$ & $2.40(0.81-7.06)$ & $42(4.4)$ \\
\hline 7. I have given or sold my prescription or my prescribed medication to someone else & $0(0.0)$ & $10(23.8)$ & $\mathrm{N} / \mathrm{A}$ & $10(1.1)$ \\
\hline $\begin{array}{l}\text { 8. I have altered my dose in some other way, for example cutting patches or pills in half, when I } \\
\text { was not advised to do so by a healthcare professional }\end{array}$ & $38(4.2)$ & $9(21.4)$ & $6.21(2.77-13.89)^{*}$ & 47 (4.9) \\
\hline $\begin{array}{l}\text { 9. I have taken my opioid medication by a different route than was prescribed, for example by } \\
\text { injecting it }\end{array}$ & $3(0.3)$ & $4(9.5)$ & $\begin{array}{l}31.58(6.83- \\
146.09)^{*}\end{array}$ & $7(0.7)$ \\
\hline $\begin{array}{l}\text { 10. I have used my opioid medication for other purposes, for example to help me sleep or to } \\
\text { help with stress or worry (do not count times when you took opioids at bedtime so that you } \\
\text { would not be in pain) }\end{array}$ & $32(3.5)$ & $4(4.4)$ & $2.87(0.96-8.51)$ & $36(3.8)$ \\
\hline
\end{tabular}

Note. Items refer to the past 3 months

Note. A $p$-value of <.005 (.05 divided by 10) was used as the cut-off for significance as each of the ten items were analysed separately.

$* p<.005$ 